\title{
O PAPEL DO BIBLIOTECÁRIO COMO MEDIADOR DA INFORMAÇÃO NA BUSCA PELO LETRAMENTO INFORMACIONAL
}

THE ROLE OF THE LIBRARIAN AS MEDIATOR OF INFORMATION IN THE SEARCH FOR INFORMATION LITERACY

${ }^{1}$ Kelly Rita de Azevedo

2Mardochée Ogécime

Universidade Federal de Minas Gerais 1,2

\section{Correspondência}

Kelly Rita de Azevedo

Universidade Federal de Minas Gerais

Belo Horizonte, MG - Brasil

E-mail: kellybibli@gmail.com

(D)ORCID: https://orcid.org/0000-0001-6908-1206

Sistema de Similaridade

\section{turnitin $\square$}

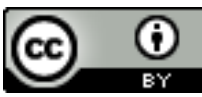

JITA: CE. Literacy.

e-Location: 020001 


\section{RESUMO}

O presente artigo discute o papel do bibliotecário como mediador da informação na busca pelo letramento informacional, focando-se em um melhor atendimento às necessidades do usuário, levando em consideração seu contexto sociocultural frente às novas demandas e dinâmicas informacionais. De uma revisão sistemática acerca da temática, empreende-se a dimensão teórico-analítica da mesma instituindo-se um traçado sobre diversas teorias interdisciplinares para a compreensão das possíveis mediações que envolvem as aproximações sucessivas desse objeto de estudo. A análise do marco teórico se baseia em uma abordagem dedutiva, partindo da descrição da particularidade do protagonismo do bibliotecário na perspectiva da sociedade da informação. Da mediação da informação nas bibliotecas à definição do papel renovado do bibliotecário diante desse fenômeno social da informação; ele, como agente mediador da informação, confronta diversos desafios, tendo destaque, o de natureza pedagógica.

\section{PALAVRAS-CHAVE}

Mediação da Informação. Letramento Informacional. Bibliotecário. Usuário da Informação.

\section{ABSTRACT}

This article discusses the role of the librarian as mediator of information in the search for information literacy, focusing on a better service to the needs of the user, taking into account their socio-cultural context against the new informational demands and dynamics. From a systematic review on the subject, the theoretical-analytical dimension of the subject is undertaken, instituting a trajectory on diverse interdisciplinary theories for the understanding of the possible mediations that involve the successive approximations of this object of study. The analysis of the theoretical framework is based on a deductive approach, starting from the description of the particularity of the role of the librarian in the perspective of the information society. From the mediation of information in libraries to the definition of the renewed role of the librarian in face of this social phenomenon of information; he, as mediator of information, confronts several challenges, with emphasis on pedagogical

\section{KEYWORDS}

Information of Mediation. Information Literacy. Librarian. Information user. 


\section{Introdução}

Partindo da perspectiva de Capurro (2003), a Ciência da Informação desenvolve-se pela evolução de três paradigmas epistemológicos inter-relacionados: o físico, o cognitivo e o social. Tais paradigmas situam os estudos de usuários da informação em distintas abordagens conforme descritas a seguir: o paradigma físico entre as décadas de 1960 a 1970 com sua abordagem tradicional e positivista, enfatizava o aspecto tecnológico, direcionado para a recuperação e transferência da informação, sem o usuário como ator principal do próprio sistema; o paradigma cognitivista que manifestou a partir de 1970, com uma abordagem alternativa, buscou compreender como o usuário assimilava e transformava a informação em conhecimento. Neste período, o usuário da informação passa a ser alvo de investigações, tendo os processos cognitivistas associados à busca, organização e uso da informação; em meados da década de 1990, a emersão do paradigma social, com uma abordagem sociocultural passa a contemplar os estudos de usuários da informação em suas relações sociais intersubjetivas, focando sobre o comportamento informacional dos mesmos. Percebe-se que tais apontamentos não são mais satisfatórios para solucionar problemas pertinentes ao uso eficiente da informação, em atendimento às suas reais e concretas necessidades para a efetiva produção de conhecimentos.

Neste contexto, os campos da Biblioteconomia e principalmente da Ciência da Informação movidos, a partir da década de 1970, pelo novo paradigma social procuraram entender o usuário a partir de suas necessidades na busca e recuperação da informação nos mais diversos suportes e fontes de informação. Desta perspectiva, a informação começa a ganhar valores significativos para diversos contextos, âmbitos e níveis e os usuários dessa nova configuração deixam de serem apenas sujeitos passivos e passam a se envolver ativamente no processo de construção da informação e conseguinte do conhecimento.

Essa concepção enfatiza a informação como um fenômeno social cujo fundamento se encontra no entendimento de que os sujeitos estão, cada vez mais, aptos a construir conhecimentos significativamente estruturados, a partir de suas interações e ações, socialmente compartilhadas, associadas às práticas informacionais coletivas, como mecanismos facilitadores ao desenvolvimento de suas competências no trato com a informação.

Sob esse ângulo, é importante ressaltar que neste efeito modernista inerente ao novo modelo de sociedade, chamada por Castells (2016) de sociedade da informação, a informação torna-se onipresente e acessível não apenas por intermédio da mídia tradicional, bem conhecida dos profissionais da informação, mas também pelas redes sociais, blogs, comunidades de usuários na Internet, etc. Ela é disseminada por meio de inúmeras características e dimensões, às vezes combinando textos, sons e imagens. Essa aparente facilidade de acesso e profusão oculta uma necessidade crescente de ferramentas e métodos para a melhor apropriação de informações relevantes para os sujeitos informacionais. 


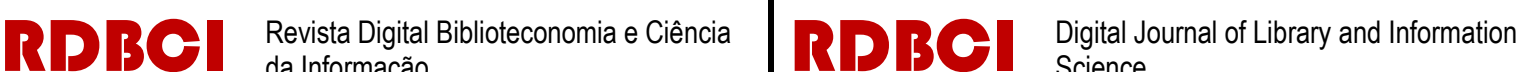

Sob essa perspectiva, os estudos de usuários são importantes instrumentos de planejamento e gestão, pois fornecem subsídios aos profissionais da informação para a identificação do perfil dos seus usuários, com o objetivo de planejar serviços e produtos para atender uma comunidade cada vez mais complexa no que tange a informação. Entre esses produtos e serviços de informação, incluem os principalmente relativos à educação e à formação do usuário e ao letramento ou alfabetização informacional, que buscam instruir os usuários no sentido de auxiliar aqueles que precisam se familiarizar com a informação sendo ela física ou digital (CUNHA, 2015).

A este propósito, o uso eficiente e criterioso da informação empreende-se, antes de tudo, dentro dos requerimentos e ações socioculturais profissionais, em saber identificar e caracterizar as necessidades informacionais. Isso evoca a capacidade de determinar as fontes relevantes, questioná-las, recuperar as informações e saber como avaliá-las. Para esse contexto, supõe-se que o desenvolvimento do letramento informacional dos usuários, exige do bibliotecário como agente mediador da informação, o protagonismo de um papel preponderante no que tangem aos afazeres biblioteconômicos. Entretanto, a adoção desse conceito confronta a biblioteca com um desafio em vários níveis.

A figura do bibliotecário protagonista vem ganhando espaço na literatura a medida que este profissional tem se envolvido cada vez mais em ações que promovam uma interação maior e mais direta com os usuários das bibliotecas, principalmente no que diz respeito a uma formação mais conscientizadora, crítica e de responsabilidade social. O desenvolvimento de competências e habilidades onde requer um posicionamento, podem auxiliar o bibliotecário a executar suas atividades de forma a antever problemas; responder prontamente aos questionamentos de forma solícita, se dispondo a aprender continuamente; utilizar os recursos disponíveis para obter sucesso nas atividades empreendidas, formulando estratégias, e mostrando-se hábil para superar obstáculos diários durante a execução de suas atividades (FARIAS, 2015).

O fortalecimento das atividades do fazer bibliotecário, no que diz respeito ao seu posicionamento crítico, tem se destacado nos estudos que abordam a postura desse profissional, que há muito tempo deixou de ser apenas tecnicista e passivo, e vem sendo modificado, principalmente, para atender um público com demandas e necessidades informacionais cada vez mais diversificadas.

Dessa consideração, o presente artigo fundamenta-se em uma dimensão teóricoanalítica da biblioteca no processo de desenvolvimento do letramento informacional dos usuários por meio da mediação da informação e assim expor o atributo de ação articulado às suas funções, seus profissionais e desafios no contexto do trabalho, lançando um olhar sociológico, pedagógico e estratégico sobre as suas propriedades. De uma revisão sistemática a respeito da temática, a análise do marco teórico se baseia em uma abordagem dedutiva, a partir da descrição da particularidade da dimensão do protagonismo biblioteconômico na perspectiva da sociedade da informação, tendo como objetivo, discutir o papel do bibliotecário como mediador da informação na busca pelo letramento informacional.

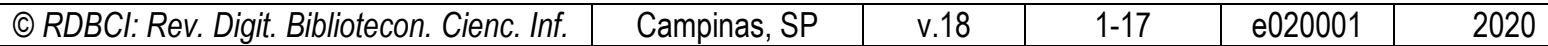




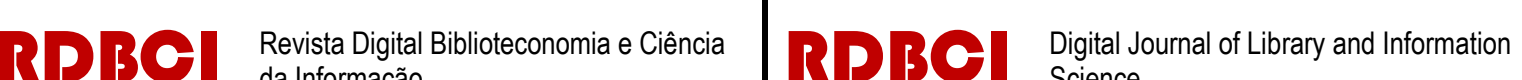

\section{A Mediação da Informação nas Bibliotecas}

Partindo de um olhar abrangente da noção de mediação e da criação de sentido, pode-se considerar que a nossa relação física com o mundo concreto é mínima, e diante dessa relação de distanciamento, como podemos conhecê-lo? Neste contexto, o autor Almeida Júnior (2015) argumenta que nós o conhecemos pelos olhos do outro; nós o conhecemos mediado pelos olhos dos outros. Somos dependentes dos outros na construção de nossos conhecimentos. O mundo que nos é mostrado não é um reflexo, mas uma refração (assim como a informação). De uma abordagem fenomenológica, pode-se dizer que o nosso conhecimento se constrói mediado e, da mesma forma, somos mediadores na construção dos conhecimentos dos outros.

Pois, para a abordagem que se queira dar a esse trabalho cujo fundamento se assenta em uma visão funcionalista e utilitarista da variável informacional que norteia a concepção da noção de 'mediação', pode-se dizer que ela é entendida como um acompanhamento, personalizado ou não, em forma de uma resposta possível à diversificação contemporânea dos usuários, suas demandas e as suas práticas, numa sociedade que se empreende numa era de informação perfilada para aperfeiçoar os processos de consumo informacional. Contudo, essa noção de mediação é aqui enfatizada sobre as funções cuja finalidade é de incentivar o desenvolvimento da autonomia do usuário para a aquisição de uma série de habilidades transversais necessárias para classificar e avaliar as informações e as suas fontes.

A mediação da informação nas bibliotecas (sejam elas escolares, universitárias, públicas ou especializadas) tem como acontecimento principal o encontro dialógico entre bibliotecários e usuários. Mediar informações requer um olhar atento para a constituição de acervos, organização dos espaços, frequência na realização das atividades culturais e práticas pedagógicas desenvolvidas nessas unidades. Entender a biblioteca do século XXI como um espaço de apropriação de conhecimento e um dispositivo cultural é tarefa a ser realizada pelos profissionais bibliotecários que fazem parte desse ambiente informacional (RASTELI; CAVALCANTE, 2014; RIBEIRO; FERREIRA, 2016).

Esta noção de 'biblioteca do século XXI' (RIBEIRO; FERREIRA, 2016), incide sobre o papel da biblioteca na conservação, disseminação, transmissão e criação de conhecimento no início do século XXI. Diante da multiplicidade de necessidades sociais e da riqueza do suporte técnico disponível para as bibliotecas, surgem muitas questões sobre como fortalecer sua presença na sociedade atual.

Esse paradigma se deve a duas grandes tendências que vêm confrontado o mundo das bibliotecas há duas décadas: primeiro, o desenvolvimento de tecnologias de informação e internet que mudou radicalmente as práticas e princípios de acesso a documentos; em segundo lugar, os bibliotecários enriqueceram o leque de suas intervenções, tornando-se gradualmente produtores de conteúdo e mediadores da informação no processo de letramento informacional, além de coletar, preservar e distribuir livros e documentos. A biblioteca do século 21 se torna um espaço de mediação da informação nos mais diversos suportes físico e digital. 
Na contemporaneidade, a noção da mediação no campo da Biblioteconomia e da Ciência da Informação vem sendo estudada principalmente no âmbito dos equipamentos informacionais, compreendidos aqui como os ambientes e as unidades de informação. Enquanto objeto de estudo destas áreas, a mediação admite vários enfoques, dentre os quais merecem destaque, a mediação da informação, da leitura e da pesquisa (CARVALHO, 2018).

Nessa vertente, considera-se que as bibliotecas, como dispositivos produtores de sentidos, permitem o acesso à informação, observando a construção de significados vivenciados através da pesquisa, da leitura, da literatura em geral, dos eventos culturais e do contato com as artes (RASTELI; CAVALCANTI, 2014). Essas responsabilidades e funções institucionais, parametrizadas nos vetores e variáveis hierárquicos, diferenciais e genéricos da cultura (BAUMAN, 2012), remetem uma importância crucial do letramento informacional na consecução dessas habilidades necessárias do usuário.

\section{Contextualização do Letramento Informacional}

A partir da década de 1970, a compreensão das necessidades, busca e uso das fontes de informações, principalmente àquelas de natureza eletrônica, por parte dos usuários, criou um conceito, cunhado nos Estados Unidos, intitulado information literacy, movimento iniciado pelos profissionais bibliotecários norte-americanos que trabalhava dentro dessa perspectiva sociocultural (TANUS, 2014). Esse conceito se intensificou no Brasil a partir da década de 2000 e assumiu diferentes feições nos estudos, como competência informacional, letramento informacional, alfabetização informacional, habilidade informacional, fluência informacional (CAMPELLO, 2003).

Desde então, o termo letramento informacional está relacionado à concepção de aprendizagem como estratégia para desenvolver habilidades informacionais. Em busca de uma dimensão mais abrangente que empreende a subjetividade do usuário da informação e o valor social da informação, o letramento informacional passa a ser conceituado como pré-requisito para o êxito da aprendizagem centrada no sujeito informacional e sua autonomia, o permitindo adquirir hábitos de leitura e atualização constante, a partir do uso adequado das ferramentas e estratégias de busca informacional, contribuindo para o desenvolvimento do pensamento crítico e responsável em relação à atuação na sociedade, sendo essencial ao aprendizado ao longo da vida. Pois, ele consiste em

[...] um processo contínuo de internalização de fundamentos conceituais, atitudinais e de habilidades necessários à compreensão e interação permanente com o universo informacional e sua dinâmica, de modo a proporcionar um aprendizado ao longo da vida. [...] pode ser considerado como o domínio sobre o universo informacional, incorporando habilidades, conhecimentos e valores relacionados à busca, acesso, avaliação, organização e difusão da informação e do conhecimento (DUDZIAK, 2003 , p. $28 ; 2002$, p. 1$)$. 
Nas sociedades onde a informação ganha um valor estratégico para o âmbito da performance e a hiperindustrialização das culturas, o letramento informacional empreende um atributo determinista, se considerando como um "farol da sociedade da informação". Ele consolida um peso relativo nas relações entre a política, a cultura e a economia para a transformação social, idealizando os caminhos para o desenvolvimento, a prosperidade e a liberdade. Nesse sentido, o letramento informacional:

- Abrange as habilidades para reconhecer as necessidades informacionais e localizar, avaliar, aplicar e criar informação dentro de contextos culturais e sociais;

- É crucial para a vantagem competitiva dos indivíduos, empresas (especialmente as pequenas e médias), regiões e nações;

- Fornece a chave para o acesso, uso e criação efetivos do conteúdo para dar apoio ao desenvolvimento econômico, à educação, à saúde e aos serviços, e a todos os outros aspectos das sociedades contemporâneas e, desta forma, fornecem os fundamentos vitais para atingir as metas da Declaração do Milênio e da Cúpula Mundial da Sociedade da Informação;

- Vão além das tecnologias atuais para abranger o aprendizado, o pensamento crítico e as habilidades interpretativas cruzando as fronteiras profissionais, além de capacitar indivíduos e comunidades (INTERNATIONAL..., 2005).

Além da sobreposição evidente do termo com as habilidades adjacentes relacionadas às tecnologias de comunicação e informação (TIC) e às referentes as mídias, o letramento informacional ambiciona ser mais abrangente, excedendo as tecnologias atuais e englobando o pensamento crítico, a interpretação da informação, bem como a produção de novos conhecimentos. Com essas ambições transversais, a implementação idealizada no seu processo de consecução das habilidades do usuário depende relativamente do contexto de aplicação. $\mathrm{O}$ nível pode variar de acordo com os requisitos institucionais, profissionais e sociais. Neste contexto, é de crucial importância entender o papel das instituições educacionais, principalmente das bibliotecas e seus agentes.

\section{Papel do Bibliotecário no Letramento Informacional}

A função educativa do bibliotecário na esfera da construção do conhecimento dos sujeitos informacionais é tema corrente nas discussões que envolvem o letramento informacional. O que ocorre em muitos casos é o desconhecimento dessas funções por parte das instituições públicas e/ou privadas onde o bibliotecário trabalha; em alguns casos por parte do próprio profissional que não se vê no papel de protagonista, principalmente no que diz respeito as atividades que envolvem um posicionamento mais crítico; além dos obstáculos de inúmeras naturezas, dentro de um movimento de corresponsabilidade.

Neste contexto, Farias (2015) discorre que a postura e a habilidade do profissional bibliotecário devem ser pautadas de acordo com as necessidades informacionais do usuário principalmente no que diz respeito ao [...] atendimento nos serviços de informação podendo

\begin{tabular}{l|c|c|c|c|c|}
\hline (c) RDBCl: Rev. Digit. Bibliotecon. Cienc. Inf. & Campinas, SP & v.18 & $1-17$ & e020001 & 2020 \\
\hline
\end{tabular}


propiciar o aprendizado e a apropriação das informações pelos usuários, para tal algumas habilidades são relevantes como: saber ouvir os usuários; procurar ser tolerante e flexível diante dos questionamentos e das diferentes posturas do outro; utilizar linguagem acessível e respeitosa; tentar construir perguntas que permitam chegar à definição esperada do tema questionado.

A este propósito, o Ministério da Educação e Cultura (MEC) elenca as Diretrizes Curriculares Nacionais (DCN) do curso de Biblioteconomia que contemplam as seguintes competências e habilidades para a formação do profissional bibliotecário, (BRASIL, 2001):

\section{a) Gerais:}

- gerar produtos a partir dos conhecimentos adquiridos e divulgá-los;

- elaborar, coordenar, executar e avaliar planos, programas e projetos;

- utilizar racionalmente os recursos disponíveis;

- desenvolver e utilizar novas tecnologias;

- traduzir as necessidades de indivíduos, grupos e comunidades nas respectivas áreas de atuação;

- desenvolver atividades profissionais autônomas, de modo a orientar, dirigir, assessorar, prestar consultoria, realizar perícias e emitir laudos técnicos e pareceres; - responder a demandas sociais de informação produzidas pelas transformações tecnológicas que caracterizam o mundo contemporâneo.

b) Específicas:

- interagir e agregar valor nos processos de geração, transferência e uso da informação, em todo e qualquer ambiente;

- criticar, investigar, propor, planejar, executar e avaliar recursos e produtos de informação;

- trabalhar com fontes de informação de qualquer natureza;

- processar a informação registrada em diferentes tipos de suporte, mediante a aplicação de conhecimentos teóricos e práticos de coleta, processamento, armazenamento e difusão da informação;

- realizar pesquisas relativas a produtos, processamento, transferência e uso da informação.

Além dessas competências e habilidades, as DCN aludem à necessidade de o currículo contemplar conteúdos de Tecnologia da Informação e Metodologia de Pesquisa. O documento também indica a importância do aspecto humanista, destacando o papel do estágio na formação profissional.

Portanto, o bibliotecário, por sua formação inicial, detém aptidões para mediar as informações que são geradas dentro dos mais diversos segmentos. Porém, quando falamos de competência para transformar as informações disponíveis em um ativo de valor agregado para o usuário, tem-se que ir um pouco mais além da formação acadêmica e do exercício da função.

A Special Libraries Association (SLA) elaborou em 2016 um relatório intitulado "Competencies for Information Professionals", que versa sobre as competências e as habilidades que os bibliotecários devem possuir para trabalhar no momento atual, em que as transformações sociais e tecnológicas acontecem muito rapidamente. De acordo com esse 
relatório, os profissionais da informação estão conectados por seu foco no gerenciamento e aplicação dos dados, informações e conhecimentos necessários na sua configuração. Eles têm uma visão holística do papel da informação e do conhecimento em organizações e comunidades, e estão preocupados com a informação e o conhecimento através de todas as etapas do seu ciclo de vida. Os profissionais da informação também estão conectados pelas competências que eles usam para realizar seu trabalho.

A atuação do profissional bibliotecário com ênfase na mediação da informação passou a ser substancial, principalmente no que diz respeito ao desenvolvimento do letramento informacional dos usuários, pois tão importante quanto possuir e disponibilizar acervos diversificados é viabilizar o uso e apropriação desse material informacional. Diante do exposto e baseado nas habilidades que um profissional bibliotecário deve possuir, a figura 1 ilustra as práticas de atuação do bibliotecário na perspectiva da mediação da informação em diversos setores.

Figura 1. As práticas de atuação profissional do bibliotecário na perspectiva da mediação da informação

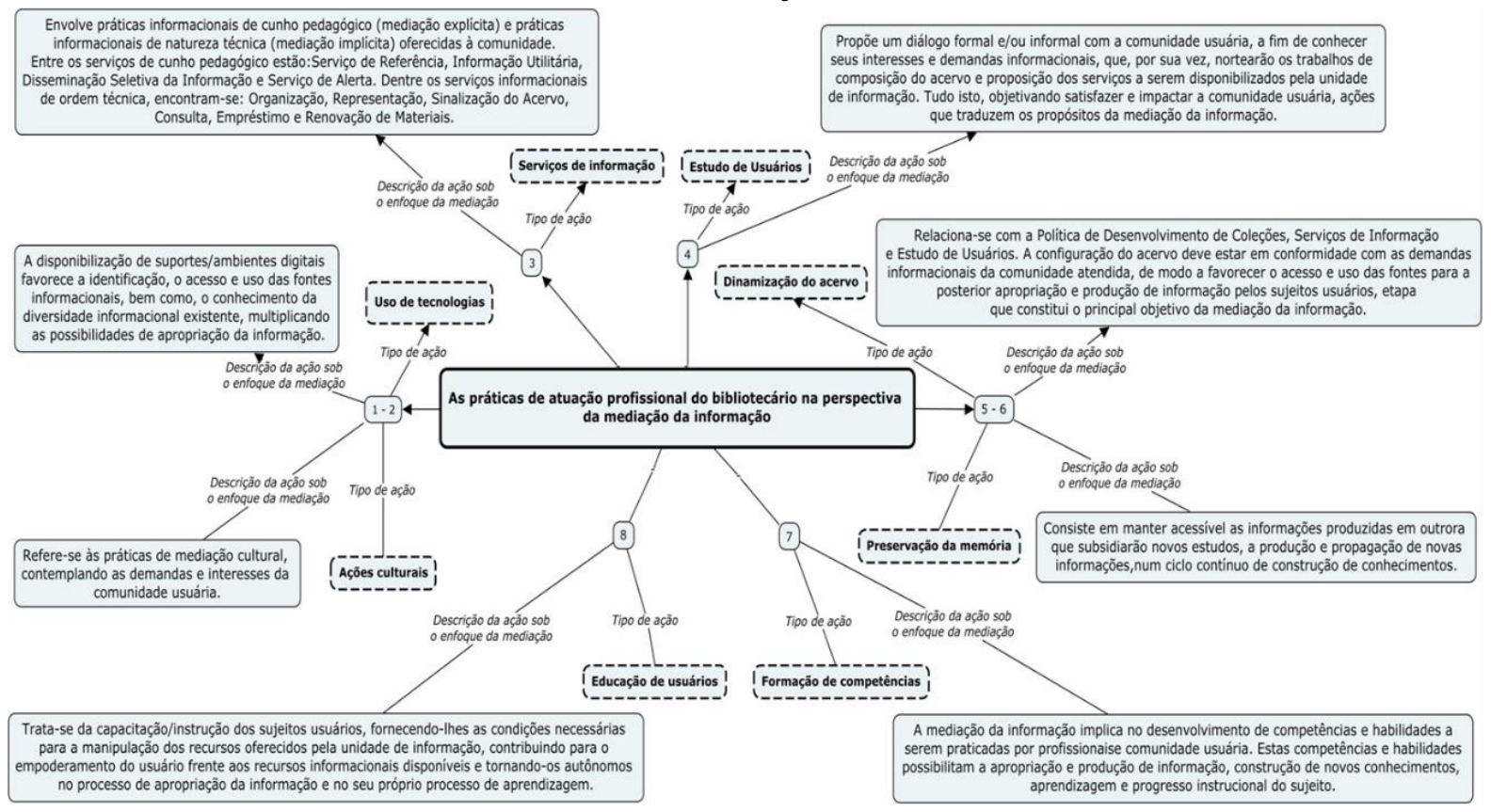

Fonte: CARVALHO, 2018 (Desenho dos autores, 2019).

De acordo com a figura 1 pode-se observar que a mediação está presente em todos os afazeres do profissional bibliotecário. Importante frisar que a mediação da informação não pode ser entendida somente como o ato de auxiliar o usuário a encontrar a informação pela qual esteja buscando, e sim como um trabalho mais profundo na busca pelo desenvolvimento de autonomia de aprendizagem desse usuário. Sendo assim, a mediação é entendida como sendo uma atividade necessária para auxiliar os usuários a transformar a informação em conhecimento, processo indispensável para o desenvolvimento do letramento informacional. 
A definição de mediação da informação, ora apresentada, é uma etapa no processo de busca e apreensão do conhecimento pelo usuário, não devendo ser vista apenas como uma ponte que liga o usuário a informação desejada. $\mathrm{O}$ mediador/bibliotecário não deve ser estático e tão pouco passivo. A mudança no comportamento do bibliotecário, passando de uma postura unicamente tecnicista para uma postura crítica, respeitando o espaço social do seu público, requer uma inovação no perfil do profissional da informação, uma inovação protagonista do seu papel nas instituições onde esse profissional atua.

\section{Desafios do Bibliotecário e da Biblioteca no Desenvolvimento do Letramento Informacional}

Na sociedade da informação, a transversalidade da informação e o uso das TIC levam à contextualização da noção do letramento informacional a um desenvolvimento conceitual que vai além das antigas abordagens biblioteconômicas. É atribuído aos bibliotecários, nesse sentido, um papel de mediação empreendido numa dimensão transversal. $O$ letramento informacional constitui, portanto, uma resposta atributiva ao questionamento da importância do papel das bibliotecas e seus profissionais frente ao surgimento da Internet e pela disponibilidade quase onipresente da informação.

Sob esse ângulo, não é suficiente ter acesso à informação (o que é possível, em certo ponto, sem a ausência de uma biblioteca); pois, o requerimento das habilidades necessárias para processar e explorar a massa de informação acrescenta uma nova responsabilidade de atribuição às bibliotecas. Para além do fornecimento, da organização e tratamento da informação, o perfil bibliotecário requer o desempenho de um papel ativo na/para a sociedade da informação (ELDREDGE, 2004).

Para além desta abordagem idealista delineada pelo manifesto da International Federation of Library Associations and Institutions (IFLA) publicada em 2005 na Biblioteca de Alexandria, intitulado Faróis da Sociedade da Informação, a noção do letramento informacional abarca também a resposta prática para os desafios do usuário frente às novas ferramentas de pesquisa e recursos digitais. Essa é, também, a razão pela qual o letramento informacional foi desenvolvido especialmente nas bibliotecas escolares e universitárias. E, como profissional com atribuição de apoiar o acesso à informação, o perfil bibliotecário passa a requerer habilidades pedagógicas (ELDREDGE, 2004). Por isso, que é atribuído hoje às bibliotecas esse desafio de se empreender como um espaço de ensino.

Esse novo papel do bibliotecário significa também novos desafios. No contexto do letramento informacional, os desafios podem ser vistos, principalmente, em três níveis: conceitual, pedagógico, estratégico e organizacional. 


\section{P BO- Revista Digital Biblioteconomia e Ciência da Informação

\subsection{Desafio conceitual}

A noção de letramento informacional vai muito além da formação tradicional dos usuários, que muitas vezes foi mais informativo do que a busca da capacitação do mesmo. Não se trata apenas de informar sobre os serviços oferecidos pela biblioteca e de ensinar o uso de ferramentas de pesquisa, trata-se de desenvolver as habilidades pessoais dos usuários que vão além da aplicação técnica (GASQUE, 2012). As ferramentas da biblioteca, portanto, servem apenas como um exemplo prático para a promoção do "saber-fazer" que pode ser ativado também em outras circunstâncias. Um usuário que aprende a definir a necessidade de informações e deduzir as palavras-chave para a pesquisa no catálogo da biblioteca pode aplicar esse método a outras ferramentas de pesquisa. No centro da busca pelo letramento informacional, estão o usuário e suas habilidades, não a biblioteca e seus recursos (GASQUE, 2012). Isso constitui uma importante mudança de perspectiva para os bibliotecários.

A ênfase do letramento informacional sobre as habilidades pessoais requer também a consideração dos contextos individuais, o que evidencia, por sua vez, a necessidade da identificação dos objetivos perseguidos pelo usuário. Pois, entender o contexto sociocultural em que está inserido o usuário pode resultar em uma tarefa muito difícil, tendo em consideração a característica fragmentada do processo de formação da identidade do sujeito moderno nas sociedades multiculturais (HALL, 2006; MANUCELLO, 2012). Neste contexto, a possibilidade de oferecer uma formação sobre tópicos necessários para promover as suas habilidades exige um estudo sociológico e antropológico muito aprofundado do usuário (ELDREDGE, 2004).

No caso das bibliotecas que operam em um ambiente educacional, a formação em letramento informacional só pode ser efetiva se ocorrer no momento oportuno, por exemplo, como parte de um projeto escolar (GOMES et al., 2016). A busca para uma melhor integração no plano de formação seria, naturalmente, a melhor solução (GASQUE, 2012). Qualquer que seja a estratégia adotada, essas iniciativas de formação podem ser coordenados com outras instituições educacionais.

Isso também ocorre porque a busca pelo letramento informacional vai além das habilidades profissionais dos bibliotecários. Pois, quando se trata do uso da informação para criar ou comunicar conhecimento, as iniciativas são, na maioria das vezes, de natureza interdisciplinar. A este propósito, a colaboração constitui um fator chave para a melhor efetivação do processo de formação em letramento informacional.

Essas iniciativas colaborativas nem sempre são fáceis. Além das barreiras institucionais, os contatos requerem ser mantidos e cuidados; muitas vezes, se encontram nas soluções e alternativas não convencionais. Foi nesse sentido que os bibliotecários estadunidenses desenvolveram o conceito de "Embedded librarians", conceito traduzido nos países iberoamericanos como "bibliotecário incorporado", que descreve um perfil de bibliotecário que atua 
em equipe com outros especialistas. (DANO; GEROGES, 2010; NAGARKAR; MURARI, 2010; CARIDAD-SEBASTIÁN; MARTÍNEZ-CARDAMA, 2013).

\subsection{Desafio pedagógico}

Também, pode dizer que a questão de disputa de fronteira epistemológica dificulta o estabelecimento e a manutenção da colaboração das instâncias pedagógicas, pois, persiste uma desconfiança natural dos pedagogos em relação à atividade dos não-pedagogos em seu campo (GABRIEL, 2010). Há, portanto, um trabalho de convicção a ser feito em relação às habilidades profissionais. Para tal fim, o empreendimento da ação interdisciplinar da Ciência da Informação, que se interessa sobre as possíveis intervenções sobre a noção da informação, é preponderante. A sua abordagem pós-moderna deve objetivar-se na efetivação desse proceder interdisciplinar promovendo a necessidade da abrangência (ou complementaridade) da formação dos bibliotecários no setor educacional. Tal complemento facilita a colaboração com os pedagogos e ajuda no entendimento da dimensão pedagógica do Estudo do Usuário (CORRÊA; SOUZA, 2004).

A noção de letramento informacional é também um conceito pedagógico que se revela, por exemplo, nas diversas normas, referências e indicadores de desempenho estabelecidos especialmente no nível universitário (GABRIEL, 2010). O propósito dessas recomendações e diretrizes, que também podem ser adaptadas a outros níveis e áreas educacionais, é definir as habilidades que constituem a busca pelo letramento informacional e diferenciar os resultados esperados do usuário no uso da informação (CAMPELLO, 2003). Essas diretrizes formam, assim, a base para a formação e a avaliação das habilidades do usuário. Para a implementação dessa pedagogia pelas habilidades, é essencial um certo conhecimento pedagógico por parte dos bibliotecários.

Para tanto, é necessário desenvolver uma 'pedagogia bibliotecária' para este propósito (ELDREDGE, 2004). Muitas vezes, é melhor aprovisionar as habilidades necessárias no campo educacional do respectivo público-alvo: pedagogia escolar, didática universitária ou educação de adultos. Tais formações contínuas, fora do ambiente da biblioteca, não complementam as habilidades dos bibliotecários-formadores, mas fornecem ao bibliotecário uma visão mais ampla sobre os seus serviços e seu público-alvo e abrangem a sua função e seu protagonismo profissional na sociedade da informação (RUSSO; JESUS DE SOUZA, 2013).

\subsection{Desafio estratégico e organizacional}

A implementação de uma oferta de formação para a busca do letramento informacional requer uma abordagem estratégica que libere recursos essenciais: capacitação de pessoal, adaptação de especificações, possível contratação de pessoal adicional, horas de trabalho extras necessárias para o desenvolvimento de conceitos pedagógicos, planos de aula e materiais didáticos, bem como o planejamento do espaço de formação. Tais recursos são defendidos, 
apenas, se a busca do letramento informacional estiver ancorada nos objetivos estratégicos da biblioteca aprovados pelos órgãos a que elas estão vinculadas.

Além disso, deve-se considerar que a transformação das bibliotecas, em um ambiente complementar de ensino, é um processo de longo prazo que deve ser planejado e acompanhado. E, uma vez atingidos os principais objetivos, a manutenção, adaptação e desenvolvimento da oferta de formação existente representam novos desafios a serem superados (KESSELMANN; WATSTEIN, 2009).

\section{Considerações Finais}

A informação como um fenômeno social, vem sendo discutida de forma mais veemente a partir da década de 1990 com o novo paradigma social, ressaltando que os sujeitos estão, cada vez mais, aptos a construir conhecimentos significativamente estruturados, a partir de suas interações e ações e o desenvolvimento de competências para com o trato da informação tornase imprescindível.

Conforme a literatura apresentada, a agregação de valor atribuída à informação como recurso nas organizações, instituições e sociedade conduziu a uma explosão exponencial da mesma. Somada à rápida evolução das tecnologias da informação e comunicação, a acessibilidade e multiplicidade de fontes de informação nos sistemas de informação, bem como a integração maciça de sistemas multimídia, levou à um crescimento da necessidade dos usuários em adquirir habilidades informacionais.

A quase onipresença da informação neste contexto vem exigindo da biblioteca e do bibliotecário, o desenvolvimento de métodos e ferramentas que viabilizem a mediação dessa informação de modo a atender às necessidades dos usuários no contexto das transformações e dinâmicas informacionais.

Para além da mediação da informação nas bibliotecas, o desenvolvimento do letramento informacional dos usuários, também passa a ser um desafio para os bibliotecários, pois a função educativa desse profissional na esfera do conhecimento coloca a importância do papel das bibliotecas não mais como uma estrutura passiva no processo e sim como ferramenta importante para a construção do conhecimento.

Esse novo papel do bibliotecário significa também novos desafios e no contexto do letramento informacional os desafios podem ser vistos, principalmente, em três níveis: conceitual, pedagógico, estratégico e organizacional.

O exercício do papel de mediador do bibliotecário requer, além das competências e habilidades profissionais exigidas, competências culturais e comunicacionais específicas, cujo 
desenvolvimento depende da superação, entre outros, de dificuldades geradas pela dispersão acadêmico-institucional dos cursos e da discussão dos papéis sociais desse profissional no desempenho de suas funções e atribuições considerando a dinâmica sociocultural nos planos global e local.

O desenvolvimento da aprendizagem se focaliza sobre o usuário e a sua autonomia, o permitindo adquirir hábitos de leitura e atualização constante, a partir do uso adequado das ferramentas e estratégias de busca informacional, e, contribuindo assim ao desenvolvimento do pensamento crítico, reflexivo e responsável em relação à sua atuação na sociedade.

Desta perspectiva, a compreensão ampla acerca do papel do bibliotecário como mediador da informação na busca pelo letramento informacional, seus desafios e desdobramentos envolvem um forte aspecto relacional, entre uma solicitação (a do usuário) e uma oferta (pelo bibliotecário com habilidades abrangentes para superar os desafios) e, portanto, uma relação de serviço diferenciado; alguns no contexto das novas dinâmicas informacionais no âmbito do delineamento da mediação da informação requerem uma reincorporação da temática na agenda dos estudos estratégicos do usuário contemporâneo da informação.

\section{Referências}

ALMEIDA JÚNIOR, Oswaldo Francisco de. Mediação da informação: um conceito atualizado. In: BORTOLIN, Sueli; SANTOS NETO, João Arlindo dos; SILVA, Rovilson José da (orgs.). Mediação oral da informação e da leitura. Londrina: ABECIN, 2015, p. 932 .

BAUMAN, Zygmunt. Ensaios sobre o conceito de cultura. Rio de Janeiro: Zahar, 2012.

BRASIL. Conselho Nacional de Educação. Diretrizes Curriculares Nacionais [Curso de Biblioteconomia]. Brasília: Ministério da Educação, 2001. Disponível em: http://portal.mec.gov.br/cne/arquivos/pdf/CES0492.pdf. Acesso em 01 jul. 2018.

CAMPELLO, Bernadete Santos. O movimento da competência informacional: uma perspectiva para o letramento informacional. Ci. Inf., Brasília, v. 32, n. 3, p. 28-37, set./dez. 2003. Disponível em: http://www.scielo.br/pdf/ci/v32n3/19021.pdf. Acesso em: 19 dez. 2018.

CAPURRO, Rafael. Epistemologia e ciência da informação. In: ENCONTRO NACIONAL DE PESQUISA EM CIÊNCIA DA INFORMAÇÃO, 5., 2003, Belo Horizonte. Anais [...] Belo Horizonte: Associação Nacional de Pesquisa e Pós-Graduação em Ciência da Informação e Biblioteconomia, 2003.

CARIDAD-SEBASTIÁN, Mercedes; MARTÍNEZ-CARDAMA, Sara. El bibliotecario integrado en el aprendizaje universitario. El profesional de la información, marzo-abril, v. 
22, n. 2, 2003. Disponível em:

http://www.elprofesionaldelainformacion.com/contenidos/2013/marzo/09.pdf. Acesso em: 02 jul. 2018.

CARVALHO, Ana Cristina Guimarães; NASCIMENTO, Maria Gezilda e Silva; BEZERRA, Midinai Gomes. A mediação da informação na narrativa oral e na história de vida:

proposições dialogais. RDBCI: Rev. Digit. Bibliotecon. Cienc. Inf., Campinas, SP, v.16, n.2, p. 461-482, maio/ago. 2018. Disponível em:

https://periodicos.sbu.unicamp.br/ojs/index.php/rdbci/article/view/8651516. Acesso em: 10 jan. 2019.

CASTELLS, Manuel. A sociedade em rede. 17. ed. rev. ampl. São Paulo: Paz e Terra, 2016.

CORRÊA, Elisa Cristina Delfini; SOUZA, Marinilva Rodrigues de. Parceria entre bibliotecário e educador: uma importante estratégia para o futuro da Biblioteca Escolar. Infociência, São Luís, v. 4, p. 68-87, 2004. Disponível em: http://www.brapci.inf.br/_repositorio/2011/04/pdf_efc6ffefda_0015923.pdf. Acesso em: 28 jun. 2018.

CUNHA, Murilo Bastos da; AMARAL, Sueli Angelica do; DANTAS, Edmundo Brandão. Manual de estudo de usuários da informação. São Paulo: Atlas, 2015.

DANO, R., MCNEELY, G. Embedded librarianship in the field. New Orleans, LA: Special Libraries Association, 2010.

DUDZIAK, Elisabeth Adriana. Information literacy: princípios, filosofia e prática.Ci. Inf., Brasília,v. 32, n. 1, p. 23-35, jan./abr. 2003. Disponível em: http://revista.ibict.br/ciinf/article/view/1016/1071. Acesso em: 05 jan. 2019.

ELDREDGE, Jonathan D. The librarian as tutor/facilitator in a problem-based learning (PBL) curriculum. Reference Services Review, v. 32, n. 1, 54-59, 2004. Disponível em: https://www.emerald.com/insight/content/doi/10.1108/00907320410519414/full/pdf?title=the -librarian-as-tutorfacilitator-in-a-problembased-learning-pbl-curriculum. Acesso em: 02 jul 2018.

FARIAS, Maria Giovanna Guedes. Mediação e competência em informação: proposições para a construção de um perfil de bibliotecário protagonista. InCID: R. Ci. Inf. e Doc., Ribeirão Preto, v. 6, n. 2, p. 106-125, set. 2015/fev. 2016. Disponível em: http://www.revistas.usp.br/incid/article/view/101368/103968. Acesso em: 10 jan. 2019.

GABRIEL, Carmen Teresa. Conhecimento escolar, universalismos e particularismos: sobre fixações de fronteira no campo do Currículo. In: ENCONTRO NACIONAL DE DIDÁTICA E PRÁTICA DE ENSINO, 15., 2010, Belo Horizonte. Anais [...]. Belo Horizonte: UFMG, 2010. Disponível em: http://endipe.fae.ufmg.br/index.php. Acesso em: 10 jan. 2019.

GASQUE, Kelley Cristine Gonçalves Dias. Letramento informacional: pesquisa, reflexão e aprendizagem. Brasília: Faculdade de Ciência da Informação / Universidade de Brasília, 2012. E-book. Disponível em: 
http://repositorio.unb.br/bitstream/10482/13025/1/LIVRO_Letramento_Informacional.pdf. Acesso em: 04 jul. 2018.

GOMES, Suely Henrique de Aquino et al. Letramento informacional: educação para a informação. Goiânia: Gráfica UFG, 2016. E-book. Disponível em: https://cafecomleitura.fic.ufg.br/up/366/o/E-book_CELI_(Corrigido).pdf. Acesso em: 02 jul. 2018 .

HALL, Stuart. A identidade cultural na pós-modernidade. Rio de Janeiro, 2006.

INTERNATIONAL FEDERATION OF LIBRARY ASSOCIATIONS AND

INSTITUTIONS. Alexandria Manifesto on Libraries: the Information Society in Action. DRAFT. Adopted in Alexandria, Bibliotheca Alexandrina, on 11 November 2005. Disponível em: http://www.cdnl.info/sites/default/files/docs/2005_cdnl05am.pdf. Acesso em: 02 jul. 2018.

KESSELMANN, Martin A.; WATSTEIN, Sarah Barbara. Creating opportunities: embedded librarians. Journal of Library Administration, v. 49, n.4, p. 383-400, 2009. Disponível em: https://www.tandfonline.com/doi/pdf/10.1080/01930820902832538?needAccess=true.

Acesso em: 02 jul. 2018.

MANUCELLO, Maria Gislaine. A formação da identidade do sujeito moderno nas sociedades multiculturais. RIDB. Ano 1, n. 11, 6779-6795, 2012. Disponível em: https://www.cidp.pt/publicacoes/revistas/ridb/2012/11/2012_11_6779_6795.pdf. Acesso em: 02 jul. 2018.

NAGARKAR, Shubhada; MURARI, Durga. Embedded librarian: a new role for library and Information professionals. Proceedings of the National Conference- on Empowering library professionals in managing the digital resources and providing extension activities held at the St Agnes College, Mangalore, 2010. Disponível em: https://www.researchgate.net/publication/304276194_EMBEDDED_LIBRARIAN_a_new_r ole_for_library_and_Information_professionals. Acesso em: 02 jul. 2018.

RASTELI, Alessandro; CAVALCANTE, Lídia Eugênia. Mediação cultural e apropriação da informação em bibliotecas públicas. Encontros Bibli: revista eletrônica de

biblioteconomia e ciência da informação, v. 19, n. 39, p. 43-58, jan./abr., 2014. Disponível em: https://periodicos.ufsc.br/index.php/eb/article/view/1518-2924.2014v19n39p43/26577. Acesso em: 02 jul. 2018.

RIBEIRO, Anna Carolina Mendonça Lemos; FERREIRA, Pedro Cavalcanti Gonçalves. Biblioteca do século XXI: desafios e perspectivas [recurso eletrônico]. Brasília: Ipea, 2016. Disponível em:

http://www.ipea.gov.br/portal/index.php?option=com_content\&view=article\&id=29215. Acesso em: 18 dez. 2018.

RUSSO, Mariza; JESUS DE SOUZA, Danyara. Biblioteca escolar brasileira na sociedade da informação: uma parceria proativa entre bibliotecário e pedagogo em prol da aprendizagem, da competência em informação e da quebra de paradigmas. In: CONGRESSO BRASILEIRO 
DE BIBLIOTECONOMIA, DOCUMENTAÇÃO E CIÊNCIA DA INFORMAÇÃO, 25. 2013, Florianópolis. Anais [...]. Florianópolis, SC, 2013. Disponível em:

https://portal.febab.org.br/anais/article/viewFile/1241/1242. Acesso em: 02 jul. 2018.

\section{SPECIAL LIBRARIES ASSOCIATION. Competencies for information}

professionals. Disponível em: https://www.sla.org/about-sla/competencies/. Acesso em 01 jul. 2018.

TANUS, Gabrielle Francinne de S. C. Enlace entre os estudos de usuários e os paradigmas da ciência da informação: de usuário a sujeitos pós-modernos. Revista Brasileira de Biblioteconomia e Documentação, São Paulo, v. 10, n. 2, p.144-173, jul/dez. 2014. Disponível em: https://rbbd.febab.org.br/rbbd/article/view/290. Acesso em: 18 dez. 2018.

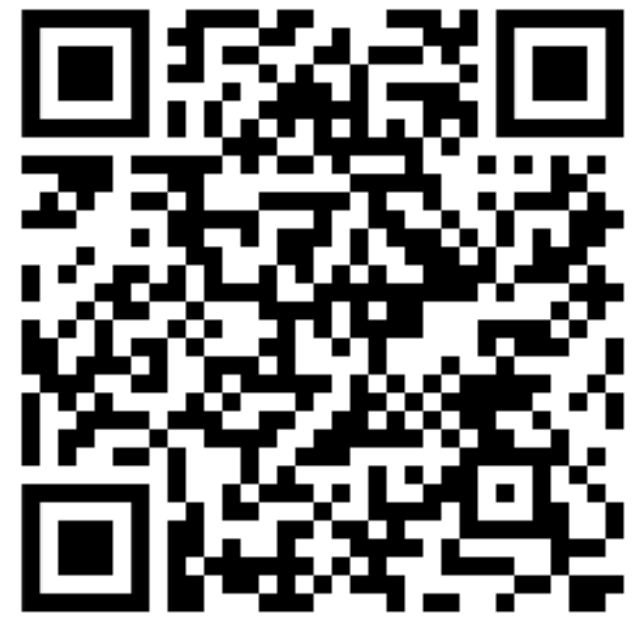

